\title{
An uncommon ovarian tumour
}

\author{
R K L S Rajapaksha ${ }^{1}$, P W C J Amarapathi ${ }^{1}$ \\ Sri Lanka Journal of Obstetrics and Gynaecology 2011; 33: 28-29
}

\begin{abstract}
Although the management of ovarian tumours is a common occurrence worldwide, management of a large granulosa cell tumour (GCT) of the ovary with concurrent endometrial cancer is relatively uncommon. We report a successful management of a case of large granulosa cell tumour with endometrial cancer in District General Hospital, Nuwara Eliya.
\end{abstract}

Key words: granulosa cell tumour, computed tomography, laparotomy.

\section{Introduction}

Granulosa cell tumours are uncommon sex cord stromal tumours ${ }^{1}$ of the ovary, which characteristically have a malignant potential, and tendency for local spread and high recurrence rate.

We report a case of a 63-year old menopausal woman, who was successfully treated for a GCT with endometrial cancer at DGH Nuwara Eliya.

\section{Case}

A 63-year old postmenopausal woman, presented to the gynaecology unit with abdominal distention and chronic abdominal pain for 4 months. She had no postmenopausal bleeding, altered bowel habits, loss of weight or appetite.

She attained menarche at 16 years of age and continued to have menstrual bleeding 3 months before being diagnosed as having a large ovarian tumour. There was no past history of ovarian tumours or family history of ovarian, breast, colonic cancers or long term use of oral contraceptive pills or hormone replacement therapy.

On examination she was haemodynamically stable, afebrile and found to have a large, firm, mobile mass arising from the pelvis equal to the size of term gravid uterus, in the distended abdomen. There was no obvious hepatosplenomegaly or abdominal tenderness.

${ }^{1}$ District General Hospital, Nuwara Eliya, Sri Lanka. Correspondence: Lasantha Sanjeewa Rajapaksha E-mail:lasanthajani@yahoo.com
Her blood investigations were normal.

Sonography revealed a huge mass extending up to the epigastrium arising from the pelvis and a contrast enhanced computed tomography was performed. It revealed a large ovarian mass with the possibility of pyometron, without significant evidence to suggest local infiltration or metastatic spread (Figure 1).

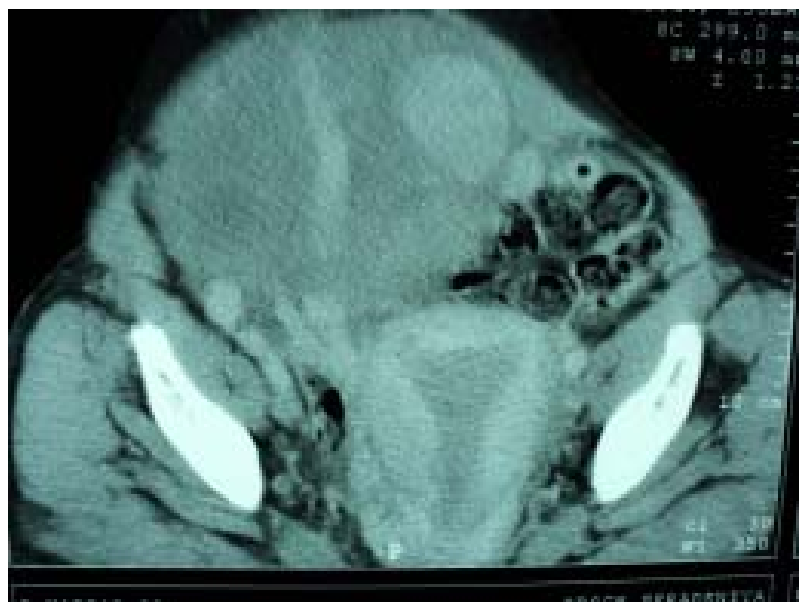

Figure 1

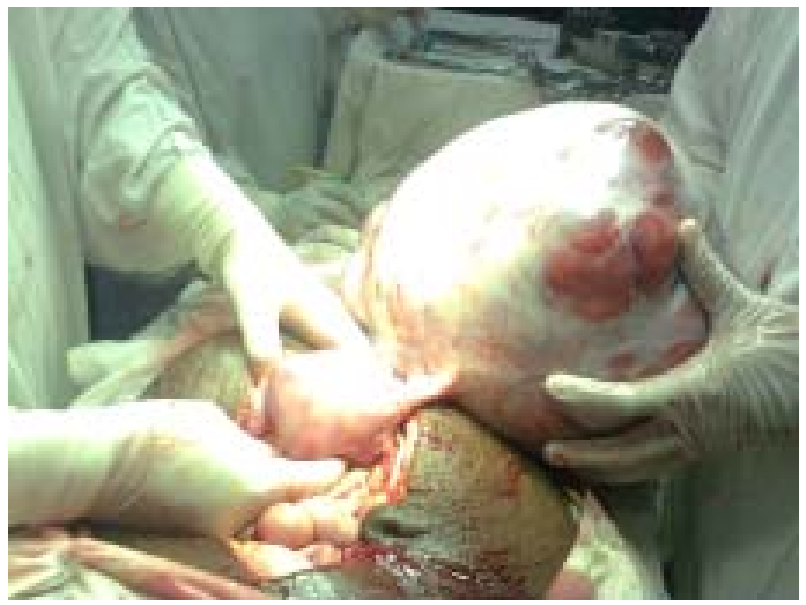

Figure 2

Staging laparotomy was carried out through a midline abdominal incision.

A large right sided ovarian tumour $(30 \times 26 \times 16$ $\mathrm{cm})$ with an enlarged uterus equal to the size of 12 
weeks gravid uterus was found. Left ovary was found to be clinically normal. Liver surface and under surface of the diaphragm was smooth. There was no enlarged pelvic or para aortic lymph nodes. Omentum was free from macroscopic deposits.

Peritoneal fluid was taken for cytology and total abdominal hysterectomy, bilateral salphingooopharectomy and omentectomy was performed on clinical suspicion of ovarian cancer. Right sided ovarian lump was dissected with the uterus, cervix and the left ovary as one block. The specimen was 7 kgs in weight (Figure 2). All specimens were sent for histo-pathological diagnosis.

The postoperative recovery was uneventful and the patient was referred to the oncologist for chemotherapy and further follow up.

Histological examination of the right ovary revealed, adult type granulosa cell tumour with a diffuse pattern. As an incidental finding, histology of the uterus revealed a well differentiated endometrioid type endometrial adenocarcinoma limited to endometrium. Both tumours were in stage Ia. Other specimens were free from malignancy.

\section{Discussion}

Granulosa cell tumours are a relatively uncommon neoplasm. Incidence of GCT is $1.6 \%$ to $3.0 \%$ in all cases of ovarian tumours and comprises approximately $10 \%$ of all cases of ovarian cancers ${ }^{2}$.
They are classified under the category of sex cord and stromal tumours of the ovary as juvenile $(5 \%)$ or adult type $\mathrm{e}^{3}$ and both sub types commonly produce oestrogen ${ }^{4}$. In a retrospective study of 74 cases of theca and granulosa cell tumours of the ovary $15 \%$ of women with theca cell tumours, endometrial adenocarcinoma was found; the same was true for $8 \%$ of women in the granulosa cell tumour group ${ }^{5}$.This factor may have contributed to the development of endometrial carcinoma in our patient.

\section{References}

1. Schumer ST, Cannistra SA. Granulosa cell tumour of the ovary. J Clin Oncol 2003; 21: 1180-9.

2. Nishi Y, Yanase T, Mu Y, Oba K, Ichino I, Saito M, Nomura M, Mukasa C, Okabe T, Goto K, Takayanagi R, Kashimura Y, Haji M, Nawata H. Establishment and characterization of a steroidogenic human granulosa-like tumour cell line, KGN, that expresses functional follicle-stimulating hormone receptor. Endocrinology 2001; 142: 437-45.

3. Chua ISY, Tan KT, Lim-Tan SK, Ho TH. A clinical review of granulose cell tumours of the ovary cases in $\mathrm{KKH}$. Singapore Med J 2000; 42(5): 203-7.

4. Young RH, Scully RE. Sex cord-stromal, steroid cell, and other ovarian tumours with endocrine, paraendocrine, and paraneoplastic manifestations. In: Kurman RJ, ed. Blaustein's Pathology of the Female Genital Tract. 4th ed. New York, NY: Springer-Verlag 1994; 783-847.

5. • iva Novak Antolic, Jule Kovacic, Srecko Rainer. Theca and granulosa cell tumours and endometrial adenocarcinoma. Gynaecology Oncology 1980; 10: 273-8. 